\title{
Foreword to special issue LeRoy Hahn
}

\author{
Terry Mader • John Nienaber • Tami Brown-Brandl
}

Published online: 5 November 2010

(C) ISB 2010

Dr. LeRoy Hahn spent his career as an Agricultural Research Service (ARS) Agricultural Engineer studying livestock housing and animal stress response. Dr. Hahn still plays an active role as an ARS collaborator at the USDAARS Meat Animal Research Center, Clay Center, NE and as Adjunct Professor Emeritus of Biological Systems Engineering at the University of Nebraska, Lincoln. He obtained his Ph.D. in Atmospheric Science from the University of Missouri-Columbia, his M.S. in Agricultural Engineering from the University of California-Davis, and his B.S. in Agricultural Engineering from the University of MissouriColumbia. With this background, Dr. Hahn has become an international leader in animal stress response and environmental impact on livestock. His leadership took the form of coordinator of the Climatic Laboratory for ARS at the University of Missouri through the 1960's until it was closed in the late 1970's. Upon closing of the Climatic Laboratory in 1978, Dr. Hahn transferred to the Environmental Laboratory at the Meat Animal Research Center in Clay Center, NE. While there, he continued to direct programs of undergraduate and graduate students at the

\footnotetext{
T. Mader $(\bowtie)$

Haskell Agricultural Laboratory, Department of Animal Science, University of Nebraska,

57905866 Road,

Concord, NE 68728, USA

e-mail: tmader@unlnotes.unl.edu

J. Nienaber $\cdot$ T. Brown-Brandl

US Meat Animal Research Center, USDA-ARS,

PO Box 166, Clay Center, NE 68933, USA

J. Nienaber

e-mail: john.nienaber@ars.usda.gov

T. Brown-Brandl

e-mail: tami.brownbrandl@ars.usda.gov
}

Universities of Nebraska and Missouri and hosted multiple international scientists as visiting professors. He served as the Research Leader of the Biological Engineering Research Unit and continued to lead and conduct research on animal stress response and techniques to ameliorate that stress. Dr. Hahn retired from the Meat Animal Research Center in August of 1997. As a researcher, he directed multiple research studies, was widely published, and served as advisor to numerous graduate students from Missouri, throughout the United States, and internationally within the general field of environmental stress and biometeorology.

Dr. Hahn's research interests includes environmental influences on stress responses and housing needs of livestock; evaluation of the dynamics of animal stress responses to environmental factors; improved characterization of environmental stressors; and development of models and climatology applications to predict farm animal performance as guides to management decisions.

Dr. Hahn has actively contributed to the International Society of Biometeorology from 1966 to the present. In addition to his work with many students, and his science contributions, he has also held the position of treasurer of ISB from 1999 to 2006.

Dr. Hahn has received numerous awards and professional recognition including the Award for Outstanding Achievement in Bioclimatology, American Meteorological Society (1976), Metal Building Manufacturers Association-American Society of Agricultural Engineers Award (1976), Norwegian Agricultural Research Council Fellowship Award for 9 months (1982-83), Elected Fellow, ASAE (1986), University of Queensland (Australia) Travel Grant Award (1997), Listed in Who's Who in America, Who's Who in Technology, Who's Who in Engineering, American Men and Women of Science Award, and for Outstanding Research Program of Livestock Environment ILES V (1997). 